\title{
Transition in modern foreign languages: a longitudinal study of motivation for language learning and second language proficiency
}

Article

Accepted Version

Courtney, L. (2017) Transition in modern foreign languages: a longitudinal study of motivation for language learning and second language proficiency. Oxford Review of Education, 43 (4). pp. 462-481. ISSN 0305-4985 doi:

https://doi.org/10.1080/03054985.2017.1329721 Available at https://centaur.reading.ac.uk/68977/

It is advisable to refer to the publisher's version if you intend to cite from the work. See Guidance on citing.

To link to this article DOI: http://dx.doi.org/10.1080/03054985.2017.1329721

Publisher: Taylor \& Francis

All outputs in CentAUR are protected by Intellectual Property Rights law, including copyright law. Copyright and IPR is retained by the creators or other copyright holders. Terms and conditions for use of this material are defined in the End User Agreement. 


\section{CentAUR}

Central Archive at the University of Reading

Reading's research outputs online 


\section{Transition in Modern Foreign Languages: a longitudinal study of motivation for language learning and second language proficiency}

\section{Louise Courtney \\ University of Reading}

The current longitudinal study examines the similarities and differences between primary and secondary foreign language curricula and pedagogy along with the development of motivation for language learning and second language proficiency. Data from 26 English learners of French (aged 10-11) were collected across three times points over a 12 month period. The study employed the use of lesson observations, along with questionnaires and focus group interviews to examine the development of attitudes and motivation. To measure linguistic progression an oral role play task, an oral photo description task and a free writing task were administered at each time point. The results show that an abrupt shift in pedagogy may negatively influence learner attitudes and motivation in early secondary and while early language learning does appear to generate positive attitudes to language learning, questions remain as to its effectiveness over the longer term when learners encounter language teaching that appears incongruous with their aims. Learners did make significant linguistic progress across the transition phase as measured by objective and fine-grained measures, which raises the question as to whether it may in fact be assessment practices that account for the reported 'hiatus' in progression across transition rather than lack of actual progress.

\section{Introduction}

Providing a smooth and effective transition from primary to secondary school has been a major longstanding challenge for educators in many subjects across the curriculum, but is a relatively recent issue facing teachers of modern foreign languages (MFL). Over the last decade, there has been a significant increase in the number of primary schools teaching a foreign language across Key Stage 2 (Tinsley \& Board, 2016) and in September 2014, foreign language teaching became a compulsory element of the National Curriculum in England in Key Stage 2 (age 7-11 years). As a consequence, a large proportion of learners now arrive in secondary school with up to four years' experience of language learning. This change has significant implications for the teaching and learning of languages across both phases since successful transition is considered crucial for the effective implementation and ultimate success of any early language learning initiative (Blondin, Calendier, Edelenbos, Johnstone, Kubanek-German \& Taeschner, 1998). While previous research has highlighted the issues of transition that are common to subjects across the curriculum, such as the 
documented 'hiatus' in progress in Year 7 (first year of secondary) and the dip in learner engagement and motivation (Galton, Gray \& Ruddock, 2003), research has shown that there are issues unique to the teaching and learning of MFL. Inconsistencies in the amount and nature of provision, and variability in the language taught at KS2 have led to increasingly heterogeneous intake in Year 7 and as a result secondary teachers face difficult decisions regarding the organisation of Year 7 language classes (Evans \& Fisher, 2009). There are, however, relatively few MFL transition studies, the majority of which have focused on attitudes and motivation, with the exception of a small number of studies by Burstall, Jamieson, Cohen and Hargreaves (1974); Graham, Courtney, Tonkyn and Marinis (2016) and Low, Brown, Johnstone and Pirrie (1995) that have incorporated an investigation of progression, attitudes and pedagogy. This paper builds on previous research by providing novel and detailed insights into the primary to secondary transition in MFL, including an examination of the similarities and differences in language pedagogy from Year 6 (final year of primary) and Year 7, and the resulting impact on learner motivation and linguistic progression.

\section{Transition across the curriculum:}

The primary to secondary transition has long been recognised as a major educational issue in the UK and across the world (e.g. see Anderson, Jacobs, Schramm and Splittgerber (2000) in the US and Pieterinen (2000) in Finland). As far back as 1977, the document 'Education in Schools (DES, 1977) highlighted notable problems at the point of $\operatorname{transfer}^{1}$ (Galton, Morrison \& Pell, 2000). Even though transition is described by Zeedyk, Gallacher, Henderson, Hope, Husband and Lindsay (2003:67) as: 'one of the most difficult [steps] in pupils' educational careers', a number of transition studies indicate that schools' transition procedures are, in general, effective in alleviating many of the children's fears and anxieties (Galton et al., 2003). Nevertheless, research in the UK has shown that discontinuities in curricula and pedagogy remain which are claimed to have an adverse impact on learner attainment and motivation. For example, Hargreaves and Galton (2000) in relation to Maths and English reported little evidence of continuity in curriculum or pedagogy and a 'hiatus' in progress (as measured by standardised tests) from the end of primary school to the end of the first year of secondary school for around $40 \%$ of learners. Similar results were reported by Galton et al. (2003), with $49 \%$ of pupils making no progress in English and Science and 33\% in Maths at the end of Year 7. However, they do note that no consistent measure of attainment was available and end of Year 7 results were based on teacher assessment

\footnotetext{
${ }^{1}$ Transfer and transition are used interchangeably in the literature
} 
and concerns have been raised about the reliability of teacher assessment across educational phases (Braund, 2009).

\section{Self-efficacy and motivation across transition}

Regarding motivation and enjoyment, the results from Galton et al. (2003) show that pupils were looking forward to going to secondary school in the few months prior to transition. These positive attitudes to secondary school remained for the first three months, but by the end of Year 7 the pupils' level of enjoyment dropped significantly. This was attributed to secondary teachers' preference for a 'fresh start' approach and lack of transfer data, findings that are mirrored by Rainer and Cropley (2013) in relation to physical education. 'Starting from scratch' is a long-standing and deliberate strategy employed by secondary school teachers which, according to Hargreaves and Galton (2000), allows secondary school teachers to gather direct information on pupil ability, rather than relying on primary school assessment data. While it could be argued that there are benefits to levelling the playing field somewhat by employing a 'tabula rasa' approach in Year 7, research shows that repeating previously learned content can have a negative impact on progression and learner motivation across a range of subjects, particularly for more able learners (Symonds, Long and Hargreaves, 2011).

For the most part, transition studies have focused on learners' perception of self-efficacy and motivation as they transfer to secondary school. Academic self-efficacy relates to the beliefs learners hold about their ability to be successful within a given subject (Bandura, 1997) and has been shown to be strongly related to academic outcomes more generally (Caprara, Vecchione, Alessandri, Gerbino \& Barbaranelli, 2011) as well as a significant predictor of subject choice (Britner \& Pajares, 2006). However, previous studies have shown that learners' perceptions of their own ability in different subjects diminishes as they move through the education system (Arens, Yeung, Craven, Watermann \& Hasselhorn, 2013) and, in particular, children's sense of competence decreases across the transition period (Cantin \& Boivin, 2004). Eccles and Midgeley (1989) attribute the observed decrease in perceived self-competence to contextual factors such as: stricter and more explicit achievement criteria and a decrease in learner autonomy. Similar findings were reported by Ward (2000) in New Zealand, who described a 'subtle disaffection' (p.373) with secondary school that was not so much related to content but to how it was delivered. 


\section{Transition in MFL}

A principal reason for the implementation of primary languages in England is the expectation that it will serve as an effective means to generate long-term, and enduring, favourable attitudes to language learning with the aim of increasing language uptake in post-compulsory phases. There are a limited number of MFLrelated studies that have examined a variety of aspects related to transition. An evaluation by Burstall et al. (1974) of the first early language teaching initiative in England and Wales concludes that poor transition and liaison arrangements contributed to the failure of the programme reporting that there was no 'significant influence' (p.242) on pupils' overall attainment and that large numbers of pupils 'failed to achieve even a modest and impermanent measure of success' (p.242). Low et al. (1995) in their cross-sectional study of young learners of French and German analysed linguistic progression and showed that learners in the first year of secondary school for the most part outperformed the primary learners. Bolster, Balandier-Brown and ReaDickens (2004) also reported a 'total lack of liaison between primary and secondary phases' (p.36) in relation to MFL which led to a perceived lack of progress and disillusionment on the part of the learners.

School approaches to transition will determine how smooth the transition will be for learners. Chambers (2014) observed that only one of the twelve secondary schools in his study had an appropriate transition policy and strategies in place. There was a notable lack of cross-phase liaison, with three of the twelve schools reporting no involvement with their feeder primary schools. This mirrors the findings of the most recent Language Trends survey (Tinsley \& Board, 2016) which reports that all of the primary schools surveyed stated they were offering language teaching during class time, but only $51 \%$ of primary schools reported having any contact with their local secondary school.

\section{Second language (L2) motivation across transition}

The findings of earlier transition studies in MFL show that motivation and enjoyment decreased over the transition period. Burstall et al. (1974) observed that pupils were initially highly motivated in primary French lessons but became significantly less so in secondary school due to repetition of content and mixedability grouping. Low et al. (1995) also reported a drop in motivation across transition. In primary school the learners viewed language lessons as fun. In contrast, the secondary school lessons had a greater focus on literacy and for some pupils this led to anxiety around spelling and accuracy. McElwee (2009) argue that the observed loss of enthusiasm for language learning in his study was due to repetition of content resulting in a lack of perceived progress, as did Hill and Ward (2003) in Australia. 
However, two recent studies have observed L2 motivational trajectories that demonstrate similarities but also notable differences with those of previous studies in MFL and other subjects. Richardson (2014) collected data from 335 learners of French and at the end of Year 6, 61\% of learners agreed that they enjoyed their language lessons. This increased to $72 \%$ at the beginning of Year 7, but by the end of Year 7 this had dropped significantly to 55\%. Language lessons were enjoyed significantly less than lessons in other subjects, although learners' perceptions of the usefulness of language learning remained stable over the year. Despite some complaints about repetition of content and lack of progression, learners' feelings of competence did increase from Year 6, but this figure decreased significantly by the end of Year 7, although did remain higher than in Year 6. Graham et al. (2016) investigated the development of learner motivation across transition in 233 learners of French. The results show that, for the most part, learners held positive attitudes to learning French at the end of year 6 and these positive attitudes remained high throughout Year 7. Again learners' perceptions of their own abilities increased significantly in all areas in Year 7, except for holding a conversation with a real French person, which is ironic since the learners cited travel and communication as their main rationale for language learning. When asked, $89 \%$ of learners said they preferred language learning in secondary school because they felt they made more progress and that lessons were more challenging. By the end of Year 7, there was a wider variation in responses between learners of different abilities: more able learners enjoyed the increased challenge of secondary language lessons, whereas lower ability learners made increasing references to the perceived difficulty of language lessons and a decrease in self-efficacy.

It is clear that the characteristics of the learning situation play a significant role in generating and maintaining positive attitudes to language learning (Bartram, 2010). While there are commonalities with other subject areas, motivation for language learning is arguably qualitatively different from other curriculum subjects. Even though learners may hold positive attitudes to language learning in general, attitudes to specific languages may differ considerably based on perceptions of usefulness, gender and national stereotypes (Bartram, 2010). The most widely-researched theory of L2 motivation is Gardner's social psychological model (Gardner, 1985). The key tenets of this model are that an individual's motivation to learn a language are influenced by two 'orientations': integrative (attitudes to the language and language speaker community) and instrumental (the perceived pragmatic benefits of learning the language), both of which are influenced by broader societal values and attitudes. However, in the early 1990s there was a call to develop L2 motivation models that have a greater focus on instructed language learning (Crookes \& Schmidt, 1991). One such model is Dörnyei's (1994) educational framework of L2 motivation that builds on Gardner's model, and comprises 
three levels: Language Level (desirability and usefulness of a specific language); Learner Level (need for achievement and self-confidence); Learning Situation Level (factors related to the course, teacher and classroom ethos). This framework is employed in the current study to capture the range of factors related to instructed L2 motivation.

While previous research has provided valuable insights into transition in MFL, the majority of studies have focused on learner attitudes and attainment data, where presented, tend to be cross-sectional. Several earlier studies have described differences in primary and secondary pedagogy and learners' reaction to this, but few, if any, studies of young learners examine in detail the interaction of pedagogy, motivation and outcomes in the same learners over time. Furthermore, to assess the development of the learners' knowledge and proficiency in French it is crucial to measure individual learner progression based on detailed, objective linguistic analyses rather than relying on broad levels of progression that may not be sufficiently detailed to capture the progress learners make over a twelve month period. The current study aims to address these gaps in knowledge in the field.

\section{Study aims and methods}

The current study addresses the following research questions:

1. What are the similarities and differences between the primary and secondary foreign language curricula and pedagogic practices?

2. To what extent does children's motivation for foreign language study develop across the transition from Year 6 to Year 7?

3. How does the children's target language proficiency develop across the transition from Year 6 to Year 7 and is there evidence of linguistic progression?

\section{Research Design}

A longitudinal mixed-method case study approach was adopted in order to generate rich, detailed data to provide a holistic view of the development of L2 progression and motivation over the transition period. Data were collected at three time points over a twelve month period: at the end of Year 6, 3 months into Year 7 and at the end of Year 7. 


\section{Participants}

Several school clusters that taught French across the whole of Key Stage 2 (age 7-11) and in Year 7 were identified and contacted. The school cluster in the current study comprised two primary schools and one secondary school in the South of England. The two primary schools had a similar profile in terms of measures of socioeconomic status (free school meals) and numbers of learners with English as an Additional Language (EAL), both of which are significantly below the national average according to government figures retrieved from www.compare-school-performance.service.gov.uk (School A EAL 0.8\%; FSM 19.6\%, School B EAL $1.5 \%$; FSM 11\%). Twenty-six children (16 girls and 10 boys) across the two primary schools participated in the study. Teachers were asked to identify learners from across the ability range, in terms of broader academic attainment, who had received four years of French teaching in primary school and who might be willing to take part in the study. Parental consent was sought and background data were verified to ensure none of the participating learners had a French-speaking parent, or significant out-of-school contact with French. All learners had English as their first language and reported no significant knowledge of additional languages. The two primary teachers were experienced primary practitioners. The teacher in School A was a general primary class teacher and had studied languages up to the end of secondary school. The teacher in School B was the languages specialist, with a French degree, who taught French to all Years 3-6 throughout the week.

\section{Data Collection Instruments}

Lesson observations were conducted in Years 6 and 7 in order to monitor the content and the process of the French lessons, as well as the contributions and engagement of the participants. An observation schedule (adapted from Cable et al., 2010 see Appendix A) was used to systematically document key aspects of each lesson. Two lessons in each primary school were observed in the Summer term of Year 6. 17 Year 7 French classes containing participating learners, with six different teachers, were observed across the Autumn and Summer terms. The qualitative analysis of the observation schedules was organised thematically based on the observed activities using Nvivo®. To gain information on teachers' rationale for primary language teaching, transition arrangements and organisational plans for Year 7, semi-structured interviews were conducted with both primary teachers and the languages coordinator in School A. Questions were related to their language background and training, school staffing model, their teaching approach, schemes of work and planning for secondary transfer. Six Year 7 French teachers were also interviewed, along with the secondary Head of MFL. 
The teachers were asked about their involvement in the transition process and planning, teaching resources, and their opinions in relation primary language teaching.

The same three language tasks were administered at each time point: a paired oral role play task, an oral photo description task and a free writing task. The teachers and schemes of work were consulted to confirm the validity of the task design and content. The tasks were designed to elicit data for an analysis of not only the learners' underlying linguistic system, but also their ability to use the language communicatively and to overcome gaps in linguistic knowledge. Moreover, it was considered essential to include tasks that reflect familiar interactive, meaning-focused classroom activities. Both the Role Play task (Appendix B) and the Photo Description task were adapted from tasks used in Cable et al. (2010) where they were shown to be effective in eliciting production data in beginner language learners. For the paired role play task the learners had to ask and answer questions related to themselves, their family and their likes and dislikes (e.g. food, sport, hobbies). The photo description task included four photographs of different scenes with which the pupils should have been familiar and required familiar vocabulary such as: parts of the body, clothes, classroom equipment. The participants were asked to describe the photographs in French. All of the instruments were successfully piloted in March and April 2010 with a small group of learners from a local primary school, who had been taught French systematically for four years. Only minor amendments to the wording of the final questionnaire items and the role play card were required. The oral tasks were recorded and transcribed in CHILDES CHAT (Codes for Human Transcription) format (MacWhinney, 2000a; 2000b). For the writing task, learners were asked to compose an email in reply to a pen pal and were instructed that they could write about any topic in a minimum of three full sentences. Written data were also transferred to CHAT and, to measure vocabulary and grammatical development, data from all three tasks a total of 234 transcriptions were analysed in CLAN (Computerized Language Analysis, MacWhinney 2000a; 2000b). For the vocabulary analysis, the transcription data were lemmatised (converted to the root form) following Tidball and Daller (2007). This is crucial to ensure that vocabulary knowledge is not over-estimated. In recognition of the learners' lack of practice in writing French learners were not penalised for spelling mistakes. Misspelled, correctly used, words were included in the vocabulary analysis which measured the number of words (tokens) and the number of types (different kinds of words) each learner produced. The analysis of the development of verb production was based on the percentage ratio of verbs per number of propositions produced. A proposition is an utterance that should ordinarily contain a verb to communicate the learners' intended meaning. For each transcription the number of propositions, with 
and without a verb included, were counted. A large proportion of the learners produced propositions that contained only noun phrases or prepositional phrases where the inferred meaning clearly required a verb. For a fuller discussion of the rationale and theoretical foundations of the selected linguistic measures see Courtney (2014).

The motivation questionnaire was based on an instrument used by Harris and Conway (2002), which itself was adapted for use with children from Gardner, Clément, Smythe, and Smythe's (1979) 'Attitude/Motivation Test Battery' which has been widely-used and empirically tested. In consideration of the age of the participants and school time constraints, the instrument was limited to 18 items with a four-point Likert scale response format and three open questions (Appendix $\mathrm{C}$ for example items). Table 1 details the mean scores and scale reliability coefficients for each round. The items were grouped into four main motivation scales that map onto Dörnyei’s (1994) framework: Language Level - Integrativeness (attitudes to language learning in general, France and French speakers); Instrumentality (usefulness; importance); Learner Level Linguistic Self-Efficacy (perceptions of their own ability in French) and Learning Situation (factors relating to lesson content, teacher and resources). Semi-structured focus group interviews with the learners were conducted at all time points, in small groups of four to six. The learners were asked if they enjoy French, what helps them to learn, whether French is different from other subjects, their perceptions of progress and the usefulness of language learning in general and of French in particular. All interviews were audio recorded, transcribed and analysed thematically in Nvivo®, with reference to Dörnyei’s (1994) framework.

\section{Results}

1. What are the similarities and differences between the primary and secondary foreign language curricula and pedagogic practices?

An analysis of school documentation and teacher interviews show that similar content topics were covered from Years 3 to 6 in both schools, for example: talking about yourself, animals, my body, my family, my school, days of the week and months, the weather, my town, holidays. Following several primary-secondary cluster meetings (around two per year, arranged by the cluster several years prior to the study), and observation visits from the secondary head of MFL, the secondary school decided to alter the Year 7 scheme of work to a 'Your School' topic because it had not been extensively covered in either of the primaries, thereby aiming to avoid simple repetition of previously learnt language. The topic did, however, permit the revision of previously 
learnt items such as numbers, colours and days of the week and the inclusion of potentially new vocabulary related to clothes and school subjects and was considered by teachers to be of interest as the learners had themselves just started a new school.

The French lessons observed in both schools displayed the characteristics commonly seen in primary French classrooms (Driscoll, Jones and Macrory, 2004). The lessons began with a 'bain français' which is an oral revision of previously learnt language as a warm up activity. Songs were also used as a warm up and a way to motivate and engage the learners, as were games using items such as beanbags. Flashcards were used in all lessons combined with choral repetition. The final part of the lessons were focussed on more literacy-based activities such as sentence matching tasks or writing one or two sentences in French based on sentence models. There was little evidence of explicit grammar instruction or any formal or informal assessment of learner progress. On the whole, the observed lessons were interactive, engaging, fast-paced and active and the emphasis was on transactional, formulaic chunks of language with little focus on explicit grammar instruction.

In Year 7, while there were some minor differences in individual teaching style from lesson to lesson, both resources and teaching approach was consistent across the classes. The findings of the observations mirror those reported in previous studies (e.g. Evans \& Fisher, 2009). On the whole the secondary lessons started on a far more formal note than in primary school. In most lessons the exercise books and textbooks were distributed first and the learners had to write the date and title in French in silence before any other activity began. Some classes began with a written starter activity such as matching pictures to word labels and recording in exercise books. Literacy-focussed activities featured heavily in the secondary lessons and there was very little observed opportunity for the learners to partake in oracy-based activities. The only opportunity to speak any French came in whole class plenary sessions with the teacher asking individuals for particular vocabulary items or translation of sentences into French. Only two Year 7 teachers made use of recorded songs in their lessons and the majority of learners participated when they were played.

Explanations of grammatical concepts and forms were far more common and were often centred round grammatical gender, highlighting the use of different articles for masculine, feminine and plural nouns and also the placement and agreement of colour adjectives. Nevertheless, these explanations normally only lasted a few minutes and appeared to feature on an ad hoc basis as the issues arose during the course of the lesson. Alongside this there was also a greater emphasis on accuracy with learners frequently reminded to check their spelling and ensure the correct use of accents. Spelling tests were a strategy often used by the teachers to encourage learners to revise vocabulary. 
2. To what extent does children's motivation for foreign language study develop across the transition from Year 6 to Year 7?

The questionnaire was administered at three time points and item scores were entered into SPSS® for analysis. The validity and reliability of the questionnaire and scales was ascertained by calculating Cronbach Alpha (CA) coefficients. Table 1 displays the group motivation mean scores, standards deviations, range and CA coefficients for rounds $1-3$.

Table 1: group motivation mean scores, standards deviations and CA coefficients rounds 1-3.

\begin{tabular}{|c|c|c|c|}
\hline Round & $\begin{array}{c}\text { Motivation } \\
\text { Mean }\end{array}$ & Range & $\begin{array}{c}\text { CA } \\
\text { Coefficient }\end{array}$ \\
\hline 1(Y6) & 3.14 & $2.19-3.88$ & .814 \\
& $(.42)$ & & \\
\hline 2(Y7a) & 3.01 & $1.94-3.75$ & .891 \\
& $(.46)$ & & \\
\hline 3(Y7b) & 3.06 & $2.31-3.81$ & .822 \\
& $(.41)$ & & \\
\hline
\end{tabular}

As seen in previous studies of young learners, the group mean scores indicate that the learners were generally positively motivated to learn French, especially at the end of Year 6 (e.g. Cable et al., 2010; Mihaljević Djigunović, 1993). The pattern of motivation, however, does not replicate that of other transition studies, for example, Galton et al. $(2000 ; 2003)$ in which a consistent drop in overall motivation across Year 7 was reported. The result of a Friedman Test of repeated measures show that the differences across the three time points are not significant $\left(\chi^{2}=5.61, \mathrm{p}=.061\right)$.

To gain a greater understanding of the nature of learner motivation, and to enable a comparison with recent MFL transition studies, mean scores across the five motivation scales were calculated and are displayed in Table 2. 
Table 2: Descriptive statistics and Cronbach alpha internal reliability coefficients for each of the motivation scales rounds 1-3

\begin{tabular}{|l|c|c|c|c|c|c|c|c|c|}
\hline \multirow{2}{*}{$\begin{array}{l}\text { Motivation } \\
\text { Scale }\end{array}$} & \multicolumn{3}{|c|}{ Round 1 } & \multicolumn{3}{c|}{ Round 2 } & \multicolumn{2}{c|}{ Round 3 } \\
\cline { 2 - 10 } & Mean & Range & $\begin{array}{c}\text { CA } \\
\text { Coefficient }\end{array}$ & Mean & Range & $\begin{array}{c}\text { CA } \\
\text { Coefficient }\end{array}$ & Mean & Range & $\begin{array}{c}\text { CA } \\
\text { Coefficient }\end{array}$ \\
\hline Instrumental & 3.38 & $2.0-4.0$ & 0.54 & 3.21 & $2.50-4.0$ & 0.63 & 3.22 & $2.0-4.0$ & 0.60 \\
Motivation (Lang) & $(0.63)$ & & & $(0.57)$ & & & $(0.76)$ & \\
\hline Integrative & 3.39 & $2.75-4.0$ & 0.55 & 3.36 & $1.75-4.0$ & 0.83 & 3.38 & $2.75-.40$ & 0.80 \\
Motivation (Lang) & $(0.51)$ & & & $(0.65)$ & & & $(0.55)$ & \\
\hline Self-Efficacy & 2.99 & $1.50-3.75$ & 0.72 & 2.98 & $2.0-4.0$ & 0.74 & 3 & $2.25-4.0$ & 0.52 \\
(Learner) & $(0.72)$ & & & $(0.62)$ & & & $(0.64)$ & \\
\hline Learning Situation & 2.98 & $1.60-4.0$ & 0.90 & 2.7 & $1.20-3.60$ & 0.81 & 2.8 & $2.25-4.0$ & 0.83 \\
& $(0.76)$ & & & $(0.81)$ & & & $(0.80)$ & & \\
\hline
\end{tabular}

Questions related to the importance of French for travel and communication purposes and French culture (Integrative) scored highest and means remained stable across the three rounds. Learners indicated that they felt relatively confident in their own ability in Year 6 and this remained consistent across Year 7 unlike the learners in Graham et al. (2016) who displayed increasing self-confidence in Year 7. While there is slight drop in mean scores for questions related to the usefulness of French for future work and study, the results of a Friedman test of repeated measures indicate that the decrease is not significant from Year 6 to end of Year 7 $\left(\chi^{2}=2.83, \mathrm{p}=.243\right)$ and learners by and large agree that learning languages is both useful and important. As in other studies (e.g. Chambers, 2000) it is the Learning Situation component that demonstrated the most variation across time with a significant decrease across the twelve months $\left(\chi^{2}=7.04, p=.03\right)$. The results of pair-wise comparisons with Bonferroni adjustment show the decrease was only significant between rounds 1 and 2 with a small effect size $(\mathrm{z}=2.43, \mathrm{p}=.015, \mathrm{r}=.29)$.

The focus group interview data corroborate these findings, in the Year 6, 77\% of learners said they enjoyed learning French. This figure dropped to $68 \%$ in term one of Year 7 but did increase slightly to $69 \%$ by the end of Year 7. In Year 6 the lessons were considered fun and interactive with activities such as songs, games and videos featuring heavily. Negative responses were infrequent but when expressed they often related to the choral repetition of words and a dislike of writing that was considered difficult and time-consuming. Despite the noticeable dip in enjoyment, there was still a wide range of activities that the learners enjoyed in their Year 7 classes: games, songs (although these were infrequent) videos and computer work. There was, however, almost unanimous agreement on what was not to like about the Year 7 lessons and that was writing/copying off the board. The learners failed to see the educational benefits and future relevance of the writing that they did in their French classes. Learners found it boring and unchallenging, and some also believe 
that it did not aid the learning of new words. Interaction and the opportunity to use the language were considered fundamental to language learning and their absence became a source of frustration for learners who felt that they did not get the opportunity to use their French interactively.

Inconsistent with findings of previous transition studies in MFL (e.g. McElwee, 2009) there was a lack of complaints regarding the repetition of content or 'starting from scratch'. The majority of learners felt that primary languages had given them a good start and a springboard from which to work and progress in Year 7. A small number of learners admitted that they were finding learning French more difficult in Year 7 . However, despite the perceived increased difficulty, most learners considered they had improved in French based on their belief that they knew more words, could write longer and more complex sentences and had a growing awareness of grammatical features. External validation by way of teacher assessment based on National Curriculum levels also enhanced their perception of progression. Nevertheless, by the end of Year 7 assessment was deemed to dominate the French lessons and the resulting pressure and anxiety felt by many of the learners contributed to the fact that secondary French lessons did not compare favourably with their primary school experience.

3. How does the children's target language proficiency develop across the transition from Year 6 to Year 7 and is there evidence of linguistic progression?

Vocabulary knowledge features prominently in the primary Programme of Study for modern foreign languages (MFL) (DfE, 2013) as does the expectation that learners will develop basic grammar knowledge including; 'the conjugation of high-frequency verbs' (p.3). As observed in previous studies of younger learners (e.g. Housen, Bulté, Pierrard \& Van Daele, 2008), vocabulary progression over time is evidenced by a generally linear increase in the number and range of words produced (although the rate of development has been shown to slow after several years of instruction). Therefore the indices of vocabulary progression in the current study are: number of words (tokens) produced and number of different word types produced. Additionally Myles (2005) argues that verb production is the first indication of emergent syntactic knowledge and therefore we would expect to see an increase in the number of verbs produced over the 12 months as indicated by the percentage ratio of verbs per number of propositions produced. The results for both measures of vocabulary and verb production for rounds 1-3 are displayed in Table 3. 
Table 3: group mean scores and standard deviations for measures of linguistic progression rounds 1-3

\begin{tabular}{|l|l|l|l|l|}
\hline \multirow{4}{*}{ Measure } & Round 1 & Round 2 & Round 3 \\
\hline & Mean no. of tokens & 161.58 & 243.85 & 304.31 \\
\cline { 2 - 5 } & Standard Deviation & 41.96 & 49.64 & 62.21 \\
\cline { 2 - 5 } & Range & $92-245$ & $177-396$ & $191-411$ \\
\cline { 2 - 5 } & Mean no. of types & 57 & 68.85 & 79.77 \\
\cline { 2 - 5 } (verb production) & Standard Deviation & 11.48 & 11.16 & 15.86 \\
\cline { 2 - 5 } & Range & $44-79$ & $52-108$ & $57-118$ \\
\cline { 2 - 5 } & Standard Deviation & 46.57 & 64.12 & 79.88 \\
\cline { 2 - 5 } & Range & $23.81-77.78$ & $18.92-82.35$ & $52.08-100$ \\
\hline
\end{tabular}

The results show that, over the transition from primary to secondary school, the learners continued to make good progress in both measures of vocabulary development. The results of a repeated measures ANOVA show that the increase was significant at all time points for both measures (tokens $\mathrm{F}=123.15, \mathrm{p}=<.001$; types $\mathrm{F}=83.91, \mathrm{p}=<.001)$. Pair-wise comparisons with Bonferroni correction indicate that differences in tokens produced are significant between all time points with large effect sizes (rounds $1-2 \mathrm{t}=7.21, \mathrm{p}=<.001, \mathrm{~d}=1.78$; rounds $2-3 \mathrm{t}=5.48, \mathrm{p}=<.001, \mathrm{~d}=0.96$; rounds $1-3 \mathrm{t}=11.74, \mathrm{p}=<.001, \mathrm{~d}=2.60)$. Results are similar for the production of word types (rounds $1-2 \mathrm{t}=6.58, \mathrm{p}=<.001, \mathrm{~d}=1.03$; rounds $2-3 \mathrm{t}=6.03, \mathrm{p}=<.001, \mathrm{~d}=0.87$; rounds $1-3$ $\mathrm{t}=9.49, \mathrm{p}=<.001, \mathrm{~d}=1.75$. While overall learners did make significant progress, it is clear from the standard deviations and range reported in Table 3, that there was a great deal of variability in both the amount and range of vocabulary produced by the learners.

Turning to verb production, Table 3 shows that the ratio of propositions containing a verb increased consistently across the transition period. The results of a repeated measures ANOVA show that this increase was again significant across all time points $(\mathrm{F}=137.61, \mathrm{p}=<.001)$. In Year 6, just under a half of utterances produced contained a verb (47\%), with most learners relying for the most part on simple noun phrases and by Year 7 this figure had increased to $80 \%$. Pair-wise comparisons with Bonferroni correction indicate that the increase in verb production is significant between all time points with large effect sizes (rounds 1-2 $\mathrm{t}=6.58$, $\mathrm{p}=<.001, \mathrm{~d}=1.24$; rounds $2-3 \mathrm{t}=6.03, \mathrm{p}=<.001, \mathrm{~d}=1.29$; rounds $1-3 \mathrm{t}=9.49, \mathrm{p}=<.001, \mathrm{~d}=2.80$ ). While learners continued to produce a greater number and range of words, verbs were the least produced word class, with nouns most common which is a common feature of language development (Bassano, 2000). Group means indicate that overall the learners made significant progress for all linguistic measures. However, as with the vocabulary scores, there was variability in performance among the individual learners (for more details on individual differences in motivation and outcomes see Courtney (2014)). 


\section{Discussion and conclusions}

It is clear that the schools involved in the current study were well aware of the issues facing them in terms of transition in relation to MFL and had begun to tackle the issue of an increasingly heterogeneous intake in Year 7. The secondary school made a creditable attempt to adjust the Year 7 scheme of work to take into account the language previously encountered, thus supporting progression for learners with previous experience, and also to make the lessons accessible and relevant to complete beginners. There were positive reactions from the pupils to the 'Our School' topic area covered in the first term of Year 7 as it provided learners with the opportunity to revise previously learnt vocabulary such as: colours and numbers, days of the week and clothing alongside new and unfamiliar language, in addition to simple grammatical structures. However, the current study shows that ensuring progression and continuity applies to both content and pedagogy, and not just content alone. The findings of the current study corroborate those of Ward (2000) who observed an abrupt shift in pedagogy across transition which resulted in a decrease in levels of enjoyment and motivation. While the learners generally held positive attitudes about their primary French lessons, their attitudes to the learning situation were more negative at the beginning of Year 7.

In the focus group interviews, when commenting on the learning situation the learners made value judgements based on four main criteria: whether the activities were intrinsically interesting, whether they aided language learning, the perceived difficulty of the tasks and activities and their perceived relevance to future goals. In Year 7 the learners became increasingly critical of their language learning experience and whether it was 'fit-for-purpose': it would seem that for many their goals seemed to be at odds with those of the teacher and curriculum. Whereas the learners were more focused on communication and speaking, the pedagogy and curriculum appeared to be aimed at passing assessments, which tended to be more literacy-focused. Primary language experience may well have exacerbated this problem as it consisted of a predominantly oracy-based pedagogy which emphasised language learning for communication purposes. Language teaching in the primary school was more in-line with the pupils' perceptions of usefulness and purpose, whereas the more assessment and literacy focussed secondary approach appeared to be more distant from the learners' own aims. The topics covered in secondary school were considered irrelevant and the learners complained about the lack of spoken interaction, and lack of opportunity to say what they wanted to say. In both primary and secondary French classes there was not much evidence of activities related to intercultural understanding and little, if any opportunity for interaction with the target language community. The results from the current study are in line 
with earlier studies that have shown that language learning in primary school cultivates positive attitudes to language learning in general (e.g. Mihaljević Djigunović, 1993; Cable at el., 2010). For the most part, the learners were still inherently interested in learning languages at the end of Year 7, but the question remains as to how effective will these favourable attitudes be in fostering and maintaining positive motivation for language learning over the longer term, when faced with a language pedagogy that appears to be incongruous with their overall objectives? Rebalancing the emphasis on literacy and oracy skills in secondary classrooms, as well as incorporating intercultural activities that provide greater target language contact such as video links, visits and online communities may help to reduce the disparity between teaching experienced and learners' objectives.

Regarding the trajectory of learner motivation and the development of learner self-efficacy from Year 6 to Year 7, the results of this and the other studies reviewed (both for MFL and other subjects) are inconsistent. This is attributable to two keys factors: inconsistency in the conceptualisation and measurement of attitudes, motivation and self-efficacy from study to study, and the influence of context and prior experience. Also, as L2 motivation theory postulates, there are numerous factors that form part of a learner's overall motivation for language study. The questionnaire responses show that overall attitudes to language learning remained relatively stable over the year, as did learners' perceptions of self-efficacy. The appraisal of self-efficacy is, however, very much related to the nature of the questions asked. The self-efficacy questions in the current study are related to oral ability only (e.g. I am getting better at speaking in French). On the other hand, the questionnaire used by Graham et al. (2016) contained self-efficacy questions related to both speaking and writing. The scores for the writing questions increased significantly in Year 7 which is undoubtedly a reflection of the more literacy-based approach in secondary school. Had questionnaire items related to literacy been included in the current study, it is likely the results would have been similar. Indeed, in the focus group interviews (reported in Courtney 2014), learners judged their progress in French on the fact that they know more words, could write longer and more complex sentences and increasing knowledge of grammar and not on speaking. Nevertheless, while overall levels self-efficacy remained stable, some learners displayed very low levels of self-efficacy across all time points and reported finding lessons increasingly difficult across Year 7. Given Block's (2007:137) assertion that pupils' self-perceptions are 'linked to the community of practice emergent inside the classroom', the growing disaffection with the language content and pedagogy suggests there is a high risk that learners will become less engaged, may doubt the achievability of their aims and ultimately give up on language study at the end of Year 9. 
A key finding of the current study, and one that contradicts many earlier studies, is that, despite the shift in language pedagogy and the fluctuations in learner motivation, the learners continued to make significant progress across the transition period in all areas investigated. The amount and range of vocabulary produced increased consistently over the year for the majority of learners. Moreover, while verb production was relatively slow to develop for some learners, there is clear progress in the amount and range of verbs produced signalling developing grammatical knowledge and productive ability. The results also support previous studies that have demonstrated that there is a great deal of variation in learner outcomes (e.g. Courtney et al. 2015) which indicates that greater differentiation in language lessons is required for learners across the ability range. While previous research has provided valuable and informative insights into motivation and progress across transition in a range of curriculum subjects, more research highlighting the differential experience and progress of learners across the ability range is needed.

It is evident that the finding of significant progression reported in the current study is attributable to the inclusion of a series of fine-grained, objective measures of language development used to evaluate learner progression, rather than reliance on broad level descriptors and teacher assessment that would have yielded less detailed information. It would be interesting and very useful to conduct future research in transition in the core subjects of English and Maths, for example, employing agreed, detailed objective measures of progression. This would help to ascertain whether it is discontinuity in grading practices that may go some way in explaining the previously reported 'hiatus' in progression, rather than solely focussing on discontinuity in content or pedagogy. Furthermore, the instruments used in the study demonstrate that one can obtain a great deal of valuable information on young learners' progression in MFL using enjoyable oral interactive tasks rather than having to rely on pencil and paper tests. While many primary teachers are reticent to introduce assessment, using activities such as those described here would provide useful and detailed information to pass on to secondary colleagues and would provide a basis for the creation of agreed cross-phase assessment practices to monitor progress across the transition period and beyond.

While the cluster of schools in the current study made a praiseworthy attempt at mediating the issues of an increasingly mixed in-take and the learners continued to make progress in all areas of investigation, it is clear that ensuring continuity in content is not sufficient on its own and that the abrupt shift in language pedagogy had a negative effect on learner attitudes. The teachers involved in the study expressed the need for greater information exchange between the two phases, and it is evident that all involved would benefit from having more mutual lesson observations to try to avoid such a marked change in language pedagogy. This is crucial for 
ensuring progression in the early stages of language learning and for maintaining motivation for language learning over the longer term. If the reasoning behind the introduction of primary languages is to encourage more children to continue with their language studies beyond the compulsory phase at secondary school then any discontinuity in approach following the transition to secondary school may in fact work contrary to these aspirations. The stated rationale for teaching languages and the objectives of the learners have to be matched with a sustained consistent pedagogy and content that is perceived as relevant for learners' communicative aims. Forcing learners to learn something they do not see as inherently valuable and interesting may actually serve to impede them in future life when they may see the need to learn a language.

\section{References}

Anderson L.W., Jacobs, J., Schramm, S. and Splittgerber, F. (2000). School transitions: beginning of the end or a new beginning? International Journal of Educational Research, 33, 325-339

Arens, K.A., Yeung, A., Craven, R.G., Watermann, R and Hasselhorn, M. (2013). Does the timing of transition matter? Comparison of German students' self-perceptions before and after transition to secondary school. International Journal of Educational Research. 57, 1-11.

Courtney, L. (2014). Moving from primary to secondary education: An investigation into the effect of primary to secondary transition on motivation for language learning and foreign language proficiency. University of Southampton.

Courtney, L., Graham, S., Tonkyn, A. and Marinis, T. (2015). Individual differences in early language learning: a study of English learners of French. Applied Linguistics. ISSN 1477-450X doi: 10.1093/applin/amv071

Bandura, A. (1997). Self-efficacy: the exercise of control. New York: W.H. Freeman.

Bartram, B. (2010). Attitudes to Modern Foreign Language Learning: Insights from Comparative Education. London, Continuum.

Bassano, D. (2000). Early development of nouns and verbs in French: exploring the interface between lexicon and grammar. Journal of Child Language, 27, 521-59.

Block, D. (2007). Second Language Identities. London: Continuum.

Blondin, C., Calendier, M., Edelenbos, P., Johnstone, R., Kubanek-German, A. and Taeschner, T. (1998). Foreign Languages in Primary and Pre-School Education: A review of recent research within the European Union. CILT.

Bolster, A., Balandier-Brown, C. and Rea-Dickens, P. (2004). Young Learners of modern foreign languages and their transition to the secondary phase: a lost opportunity? Language Learning Journal, 30, 35-41.

Braund,M. (2009). Primary-Secondary Transfer in Science. Perspectives on Education, Issue 2, Spring 2009. Wellcome Trust. 
Britner, S. and Pajares, F. (2006). Sources of science self-efficacy beliefs of middle school students. Journal of Research in Science Teaching, 43,5, 485-499.

Burstall, C., Jamieson, M., Cohen, S. and Hargreaves, M. (1974). Primary French in the Balance. Windsor, NFER Publishing Company.

Cable, C., Driscoll, P. and Mitchell, R. (2010). Languages Learning at Key Stage 2: A Longitudinal Study. London: DCSF. Available at https://www.education.gov.uk/publications/eOrderingDownload/DCSF-RR198.pdf

Cantin, S. and Boivin, M. (2004), Change and stability in children's social network and self-perceptions during transition from elementary to junior high school. International Journal of Behavioural Development 28, 6, 561570

Caprara, G.V., Vecchione, M., Alessandri, G., Gerbino, M., and Barbaranelli, C. (2011). The contribution of personality traits and self-efficacy beliefs to academic achievement: a longitudinal study. British Journal of Educational Psychology 81, 1, 78-96.

Chambers, G. (2000). Motivation and the Learners of Modern Languages. In S. Green (Ed) New Perspectives on Teaching and Learning Modern Languages (46-76). Clevedon, Multilingual Matters.

Chambers, G. (2014). Transition in modern languages from primary to secondary school: the challenge of change. The Language Learning Journal 42, 3, 242-260

Crookes, G., \& Schmidt R. W. (1991). Motivation: Reopening the research agenda. Language Learning, 41, 4, 469-512.

Department for Education (2013). National Curriculum Framework Document available at http:www.gov.uk/government/uploads/system/uploads/attachment_data/file/210969/NC_framework_document_ -_FINAL.pdf

Department of Education and Science (1977). Curriculum 11-16. London: HMSO Publications

Dörnyei, Z. (1994). Motivation and Motivating in the Foreign Language Classroom. The Modern Language Journal, 78, 3, 273-284.

Driscoll, P, Jones, J and Macrory, G. (2004). The Provision of Foreign Language Learning for Pupils at Key Stage 2. http://www.dfes.gov.uk/research/data/uploadfiles/RR572.pdf

Eccles, J.S. and Midgeley, C. (1989). Stage/environment fit: Developmentally appropriate classrooms for early adolscents. In R. Ames and C. Ames (Eds.) Research on Motivation in Education (Vol 3, 139-181). New York, Academic Press.

Evans, M. and Fisher, L. (2009). Language Learning at Key Stage 3: The impact of the Key Stage 3 Modern Foreign Language Framework and Changes to the Curriculum on Provision and Practice. DCSF RR091. http://www.dcsf.gov.uk/research/data/uploadfiles/DCSF-RR091.pdf 
Galton, M., Gray, J. \& Ruddock, J. (2003). Transfer and transition in the middle years of schooling (7-14): Continuities and discontinuities in learning. Department for Education and Skills, Research Report RR443, Nottingham, DfES Publications.

Galton, M., Morrison, I. \& Pell, T. (2000). Transfer and transition in English schools: reviewing the evidence. International Journal of Educational Research, 33, 4, 341-363.

Gardner, R. (1985). Social psychology and second language learning: The role of attitudes and motivation. London, Edward Arnold.

Gardner, R.C., Clément, R., Smythe, P.C. and Smythe, C.L. (1979). The Attitude/Motivation Test Battery revised manual. Research bulletin No. 15. London, Canada: Language Research Group, University of Western Ontario.

Graham, S., Courtney, L., Tonkyn, A. and Marinis, T. (2016). Motivational trajectories for early language learning across the primary-secondary school transition. British Educational Research Journal. ISSN 14693518 doi: $10.1002 /$ berj.3230

Hargreaves, L. \& Galton, M. (2000). (Eds.), Moving from the primary classroom: 20 years on. London: Routledge.

Harris, J. and Conway, M. (2002). Modern Languages in Irish Primary Schools: An evaluation of the National Pilot Project. Dublin, Institiúid Teangeolaíochta Eireann.

Hill, K. and Ward, S. (2003). Passing the baton: the transition from primary to secondary language programs. New Zealand Studies in Applied Linguistics, 9, 2, 19-36.

Housen, A, Bulté, B., Pierrard, M. and Van Daele, S. (2008). Investigating lexical proficiency development overtime: the case of Dutch-speaking learners of French in Brussels. French Language Studies, 18, 1-22.

Hunt, M., Barnes, A., Powell, B. and Martin, C. (2008) Moving on: The challenges for foreign language learning on transition from primary to secondary school. Teaching and Teacher Education, 4, 915-926

Low, L., Brown, S., Johnstone, R. and Pirrie, A. (1995). Foreign Languages in Primary Schools: Evaluation of the Scottish Pilot Projects 1993-1995 Final Report. Scottish CILT Publication.

McElwee, J. (2009). CILT 7-14 project 2008/9 Final Report - Learning Networks. www.cilt.org.uk/secondary/transition/redcar_cleveland.aspx

MacWhinney, B. (2000a). The CHILDES Project: Tools for Analyzing Talk. 3rd

Edition. Vol 1: The Format and Programs. Mahwah, NJ, Lawrence Erlbaum Associates.

MacWhinney, B. (2000b). The CHILDES Project: Tools for Analyzing Talk. $3^{\text {rd }}$ Edition. Vol 2: The Database. Mahwah, NJ, Lawrence Erlbaum Associates.

Mihaljević Djigunović, J. (1993). Investigation of attitudes and motivation in early foreign language learning. In M. Vilke and Y. Vrhovac (eds.) Children and Foreign Languages (45-71). Zagreb: Faculty of Philosophy, University of Zagreb

Myles, F. (2005). The Emergence of Morpho-syntactic Structure in French L2. In J-M. Dewaele (Ed.) Focus on French as a Foreign Language (88-113). Clevedon, Multilingual Matters. 
Pieterinen, J. (2000) Transfer to and study at secondary school in Finnish school culture: developing schools on the basis of pupils' experiences. International Journal of Educational Research 33, 383-400

Rainer, P. and Cropley, B. (2013) Bridging the gap - but mind you don't fall. Primary physical education teachers' perceptions of the transition process to secondary school. Education 3-13

DOI:10.1080/03004279.2013.819026

Richardson, K. (2014) What can we learn from the pupils? Transition from KS2 to KS3, paper presented at the Association for Language Learning (ALL) Language World Conference, University of Lancaster, 4 April.

Sutherland, R. McNess, E., Yee, W.C. and Harris, R. (2010). Supporting learning in the transition from primary to secondary schools. Merchant Venturers.

Symonds, J., Long, M. and Hargreaves, J. (2011). Changing Key: Adolescents'views on their musical development across the primary to secondary school transition. Paul Hamlyn Foundation.

Tidball, F. and Treffers-Daller, J. (2007). Exploring measures of vocabulary richness insemi-spontaneous French speech: A quest for the Holy Grail? In: H. Daller, J. Milton and J. Treffers-Daller (eds). Modelling and Assessing Vocabulary Knowledge (133-149). Cambridge, Cambridge University Press.

Tinsley, T and Board, K. (2016). Language Trends 2015/16: The state of language learning in primary and secondary schools in England. British Council/Educational Development Trust. Available online at: https://www.britishcouncil.org/sites/default/files/language trends_survey 2016 0.pdf

Ward, R. (2000) Transfer from middle to secondary school:a New Zealand study. International Journal of Educational Research 33, 365-374.

Zeedyk, S., Gallacher, J., Henderson, M., Hope, G., Husband, B., and Lindsay, K. (2003). Negotiating the transition from primary to secondary school: Perceptions of pupils, parents and teachers. School Psychology International 24, 1, 67-79. 